\title{
Effect of Nd content on microstructure and mechanical properties of as-cast $\mathrm{Mg}-12 \mathrm{Li}-3 \mathrm{Al}$ alloy
}

\author{
*Tian-shun Dong, Xiao-dong Zheng, Tuo Wang, Jin-hai Lliu, and Guo-lu Li \\ School of Materials Science and Engineering, Hebei University of Technology, Tianjin 300132, China
}

\begin{abstract}
In order to improve the mechanical properties of Mg-Li alloy with single $\beta$ phase structure, Mg- $12 \mathrm{Li}-$ $3 \mathrm{Al}-x \mathrm{Nd}(x=0.3,0.7,1.1,2.0 \mathrm{wt} . \%)$ alloy was prepared. Subsequently, the as-cast microstructure and mechanical properties were observed and tested. The results showed that the structure of Mg-12Li-3Al- $x \mathrm{Nd}(x=0.3,0.7,1.1$, 2.0wt.\%) as-cast alloy was composed of $\beta$ phase matrix and $\mathrm{Al}_{2} \mathrm{Nd}, \mathrm{Al}_{11} \mathrm{Nd}_{3}, \mathrm{MgLiAl}_{2}, \mathrm{Al}_{4} \mathrm{Li}_{9}$ and $\mathrm{AlLi}_{\text {phases. With }}$ the increase of $\mathrm{Nd}$ content in the alloy, the Al-Nd intermetallic compounds have a trend to change from needle-like $\mathrm{Al}_{11} \mathrm{Nd}_{3}$ to granular $\mathrm{Al}_{2} \mathrm{Nd}$. The hardness of as-cast Mg-12Li-3Al- $x \mathrm{Nd}(x=0.3,0.7,1.1,2.0 \mathrm{wt} . \%)$ alloy was stable at room temperature. The tensile strength of $\mathrm{Mg}-12 \mathrm{Li}-3 \mathrm{Al}-1.1 \mathrm{Nd}$ was as high as $180 \mathrm{MPa}$, the elongation rate of $\mathrm{Mg}$ $12 \mathrm{Li}-3 \mathrm{Al}-0.7 \mathrm{Nd}$ reached $53.7 \%$, and the comprehensive mechanical properties of $\mathrm{Mg}-12 \mathrm{Li}-3 \mathrm{Al}-2.0 \mathrm{Nd}$ was the best. PLC phenomenon occurred during the tensile process of the alloys at room temperature. Therefore, the $\beta$-based $\mathrm{Mg}-\mathrm{Li}$ alloy with good plasticity as well as enhanced strength can be obtained by a moderate addition of $\mathrm{Nd}$ and $\mathrm{Al}$.
\end{abstract}

Key words: Mg-Li; $\beta$; Nd; microstructure; mechanical properties

CLC numbers: TG146.22 Document code:AＡrticle ID: 1672-6421(2017)04-279-07

\begin{abstract}
A $\mathrm{s}$ the lightest metal structural material today, magnesium lithium alloy is widely used in aerospace and military fields, and has broad application prospects in the fields of automobile, electronics, medical products and so on ${ }^{[1]}$. Although magnesium lithium alloy has many excellent properties such as high strength and high stiffness ratio, strong cold and hot deformation ability and no obvious anisotropy, but it has also some obvious weaknesses. For example, the absolute strength is low, creep resistance and corrosion resistance are poor $^{[2,3]}$, so strengthening the magnesium lithium alloy has become a key to expanding its application fields. Scholars at home and abroad have done much work on how to strengthen Mg-Li alloy ${ }^{[4-6]}$.

It can be seen from the binary-phase diagram of $\mathrm{Mg}-\mathrm{Li}$ alloy that, according to the difference of Li content, $\mathrm{Mg}$ Li alloy has three kinds of structure, i.e. $\alpha$ phase, $\alpha+\beta$ phase and $\beta$ phase ${ }^{[7]}$. When the lithium content is greater than $10.3 \%$, the structure is single $\beta$ phase (body-centred
\end{abstract}

\footnotetext{
*Tian-shun Dong

Male, born in 1968, associate professor. His research interests mainly focus on material forming technology research.

E-mail: dongtianshun111@163.com

Corresponding author: Jin-hai Liu, email: jhliu57@126.com
}

Received: 2017-02-16; Accepted: 2017-05-01 cubic). The plasticity of $\beta$ phase is much higher than that of $\alpha$ phase; its density is $1.3-1.5 \mathrm{~g} \cdot \mathrm{cm}^{-3}$, and with the increase of Li content, its density linearly decreases. LA141A is a typical commercial magnesium lithium alloy with single $\beta$ phase structure available today. But $\beta$ is a softer phase compared with $\alpha$, and creep of $\beta$-based $\mathrm{Mg}-\mathrm{Li}$ alloy is likely to occur even when the stress is small, since its strength is low despite of the good plasticity.

$\mathrm{Nd}$ is one of the most prominent rare earth elements, and has good purification, modification and alloying effects on many nonferrous metal materials ${ }^{[8]}$. The addition of $\mathrm{Nd}$ in magnesium or aluminum alloy can effectively improve air tightness, corrosion resistance and mechanical properties ${ }^{[9-12]}$. Therefore, this study intends to prepare $\beta$-based $\mathrm{Mg}$-Li alloy with good plasticity as well as enhanced strength by adding $\mathrm{Nd}$ and $\mathrm{Al}$ element. Furthermore, this study has some reference value for expanding the application of $\mathrm{Mg}$-Li alloy.

\section{Composition design and experimental procedures}

\subsection{Content of $\mathrm{Li}, \mathrm{Al}$ and $\mathrm{Nd}$}

Although aluminum element has good solid solution 
strengthening effect on $\mathrm{Mg}-\mathrm{Li}$ alloys, with the increase of $\mathrm{Al}$ content, the ductility of $\mathrm{Mg}-\mathrm{Li}$ alloy decreases. Moreover, in a certain temperature range, when the mass fraction of $\mathrm{Al}$ is greater than $4 \%$, the $\beta$ single phase region will disappear ${ }^{[13]}$. Therefore, in this study, using LA141A as a reference, the alloy prepared was expected to have not only good ductility due to single $\beta$ phase structure, but also enhanced tensile strength, so the content of $\mathrm{Li}$ and $\mathrm{Al}$ were determined to be $12 \%$ and $3 \%$, respectively.

Rare earth elements have low solid solubility in Mg-Li alloy, but can refine the structure of $\mathrm{Mg}-\mathrm{Li}$ alloy and form a variety of intermetallic compound, which can increase the strength and improve the thermal stability of $\mathrm{Mg}$-Li alloy ${ }^{[14]}$. In addition, rare earth elements can narrow the solidification temperature range of the alloy and improve the compactness of the casting ${ }^{[15,16]}$. Nevertheless, the excess addition of rare earth will lead to the coarsening of grains and the significant increase of density for $\mathrm{Mg}-\mathrm{Li}$ alloy, hence the content of $\mathrm{Nd}$ is determined to be $0.3 \%-$ $2.0 \%$ in this study.

\subsection{Materials}

The main raw materials were pure magnesium ingot $(\mathrm{Mg} \geqslant 99.95 \%)$, pure lithium of battery grade (in fragmented, Li content $\geqslant 99.9 \%$ ), bulk $\mathrm{Mg}-25 \mathrm{Nd}$ master alloy and $\Phi 5 \mathrm{~mm}$ aluminum wire $(\mathrm{Al} \geqslant 99.9 \%)$.

\subsection{Methods and equipment}

The alloy was melted in a vacuum resistance melting furnace (Model: ZRRL-M8). The mold should be prepared with coating and preheated to about $300{ }^{\circ} \mathrm{C}$ before casting. The specific gravity was measured by the Archimedes method, and the quality of the alloy was measured by a balance with an accuracy of $1 / 10000$ grams.

The microhardness of the alloy prepared was determined by a Digital Micro-hardness Tester. The test load was 980.7 $\mathrm{mN}$ (100 gf) and the holding time was $30 \mathrm{~s}$. Each sample was randomly detected at 5 points and the results were averaged. The microstructure was observed and analyzed using SEM (scanning electron microscopy, PHILIPS XL30W/TMP, scanning voltage $20 \mathrm{kV}$ ) and EDS (energy dispersive spectrometer). The phase analysis of the alloy was conducted by means of X-ray diffraction apparatus $(\mathrm{D} / \mathrm{max}-2500)$. The tensile properties at room temperature of the as-cast alloy were measured on a numerical controlled thermal physical simulation machine (Gleeble1500D). The test load was $8,160 \mathrm{~kg}$ and the tensile speed was $1.2 \mathrm{~mm} \cdot \mathrm{min}^{-1}$.

\section{Results and discussion}

\subsection{Composition and density}

According to the addition amount of rare earth element $\mathrm{Nd}$, four kinds of alloy were designed and prepared. The chemical composition and density of the alloys are shown in Table 1. As can be seen from Table 1, the actual composition of the Mg-LiAl-Nd alloy prepared is basically close to that of the design. The density of alloys is relatively low on the whole, and the density of \#1 alloy is the lowest.

Table 1: Chemical composition and density of alloy

\begin{tabular}{|c|c|c|c|c|c|c|c|c|c|}
\hline \multirow{2}{*}{$\begin{array}{l}\text { Number } \\
\text { of alloy }\end{array}$} & \multirow{2}{*}{ Alloy } & \multicolumn{2}{|c|}{ Li (wt.\%) } & \multicolumn{2}{|c|}{ Al (wt.\%) } & \multicolumn{2}{|c|}{ Nd (wt.\%) } & \multirow{2}{*}{$\underset{\text { (wt. \%) }}{\text { Mg }}$} & \multirow{2}{*}{$\rho\left(g^{\circ} \mathrm{cm}^{-3}\right)$} \\
\hline & & $\begin{array}{l}\text { Design } \\
\text { content }\end{array}$ & $\begin{array}{l}\text { Actual } \\
\text { content }\end{array}$ & $\begin{array}{l}\text { Design } \\
\text { content }\end{array}$ & $\begin{array}{l}\text { Actual } \\
\text { content }\end{array}$ & $\begin{array}{l}\text { Design } \\
\text { content }\end{array}$ & $\begin{array}{c}\text { Actual } \\
\text { content }\end{array}$ & & \\
\hline$\# 1$ & Mg-12Li-3Al-0.3Nd & 12 & 13.02 & 3 & 3.44 & 0.4 & 0.30 & bal. & 1.4759 \\
\hline \#2 & Mg-12Li-3Al-0.7Nd & 12 & 11.72 & 3 & 2.88 & 0.8 & 0.72 & bal. & 1.4936 \\
\hline \#3 & Mg-12Li-3Al-1.1Nd & 12 & 13.21 & 3 & 3.10 & 1.2 & 1.05 & bal. & 1.5018 \\
\hline \#4 & Mg-12Li-3Al-2.0Nd & 12 & 11.66 & 3 & 2.74 & 2.0 & 1.99 & bal. & 1.5351 \\
\hline
\end{tabular}

\subsection{Metallographic structure}

Figure 1 shows the SEM micrograph of Mg-12Li-3Al-0.3Nd alloy. It can be seen from Fig. 1 that the matrix is single phase structure with some gray particles on it. XRD analysis results in Fig. 2 further indicate that the matrix of the alloy is single phase $\beta(\mathrm{Li})$, the gray particles in Fig. 1 are $\mathrm{MgLiAl}_{2}, \mathrm{AlLi}$ and $\mathrm{Al}_{4} \mathrm{Li}_{9}$, which give a precipitation strengthening effect on the matrix. In addition, there is a small amount of white acicular phase in the matrix, which is $\mathrm{Al}_{11} \mathrm{Nd}_{3}$ and has been confirmed by relevant literature $^{[10,12]}$

Figure 3 shows the SEM micrograph of Mg-12Li-3Al-0.7Nd alloy and the EDS analysis of the white granular phase. It can be seen that there is much $\mathrm{Al}$ and $\mathrm{Nd}$ in the white granular phase. Due to the small particle size and large amount of $\mathrm{Mg}$ in the matrix, the peak of $\mathrm{Mg}$ was obtained in the EDS analysis. Figure 4 shows the XRD results of $\mathrm{Mg}-12 \mathrm{Li}-3 \mathrm{Al}-0.7 \mathrm{Nd}$ alloy, which indicates that the matrix is composed of single phase $\beta(\mathrm{Li})$, containing $\mathrm{Al}_{2} \mathrm{Nd}, \mathrm{Al}_{11} \mathrm{Nd}_{3}$ intermetallic compounds and a small amount of $\mathrm{MgLiAl}_{2}$ and $\mathrm{Al}_{4} \mathrm{Li}_{9}$. Combined with the EDS analysis results, it can be inferred that the white granular phase in Fig. 4(a) is $\mathrm{Al}_{2} \mathrm{Nd}$, the small amount of white acicular phase was $\mathrm{Al}_{11} \mathrm{Nd}_{3}$ and the gray particles were $\mathrm{MgLiAl}_{2}$ and $\mathrm{Al}_{4} \mathrm{Li}_{9}$. 


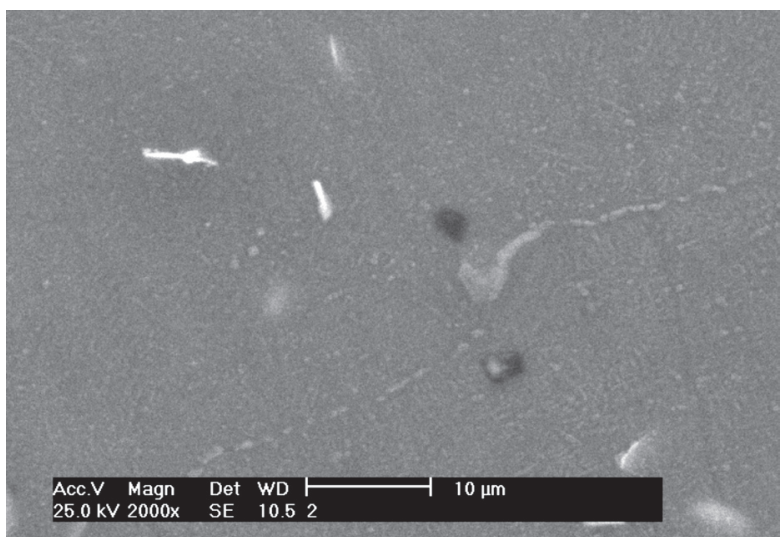

Fig. 1: Microstructure of Mg-12Li-3Al-0.3Nd alloy

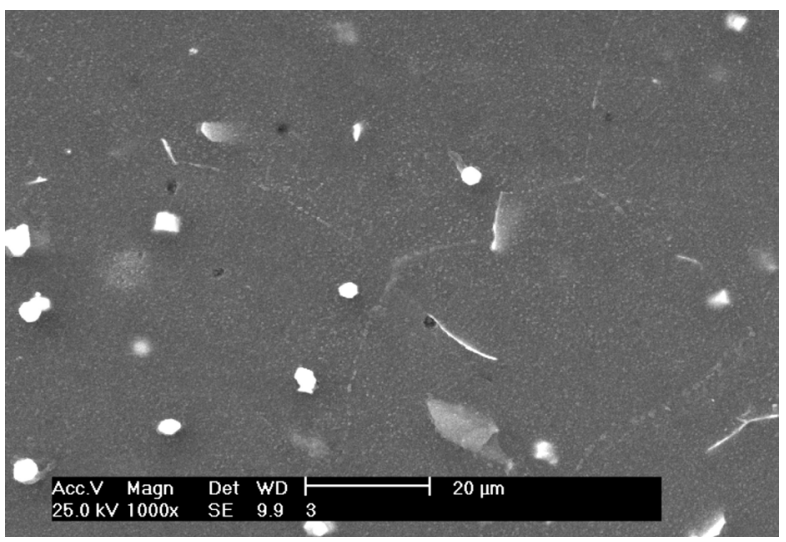

Fig. 3: Microstructure (a) and EDS analysis (b) of Mg-12Li-3Al-0.7Nd alloy

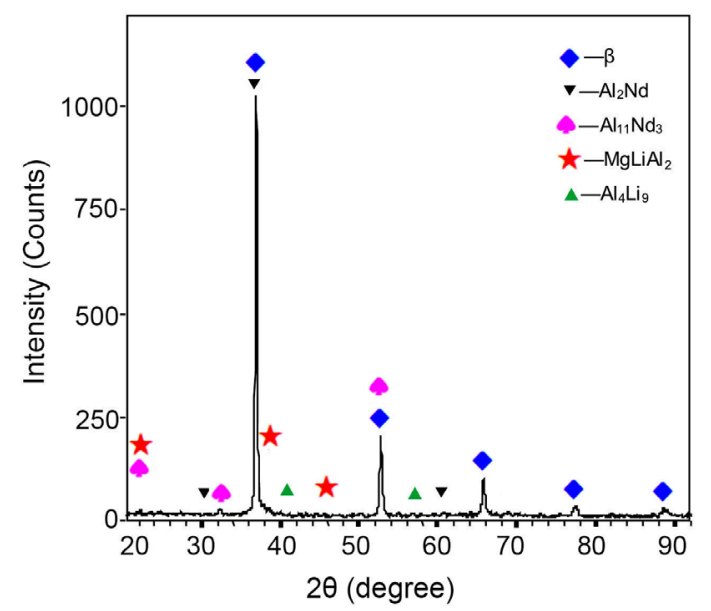

Fig. 4: X-ray diffraction pattern of Mg-12Li-3Al-0.7Nd alloy
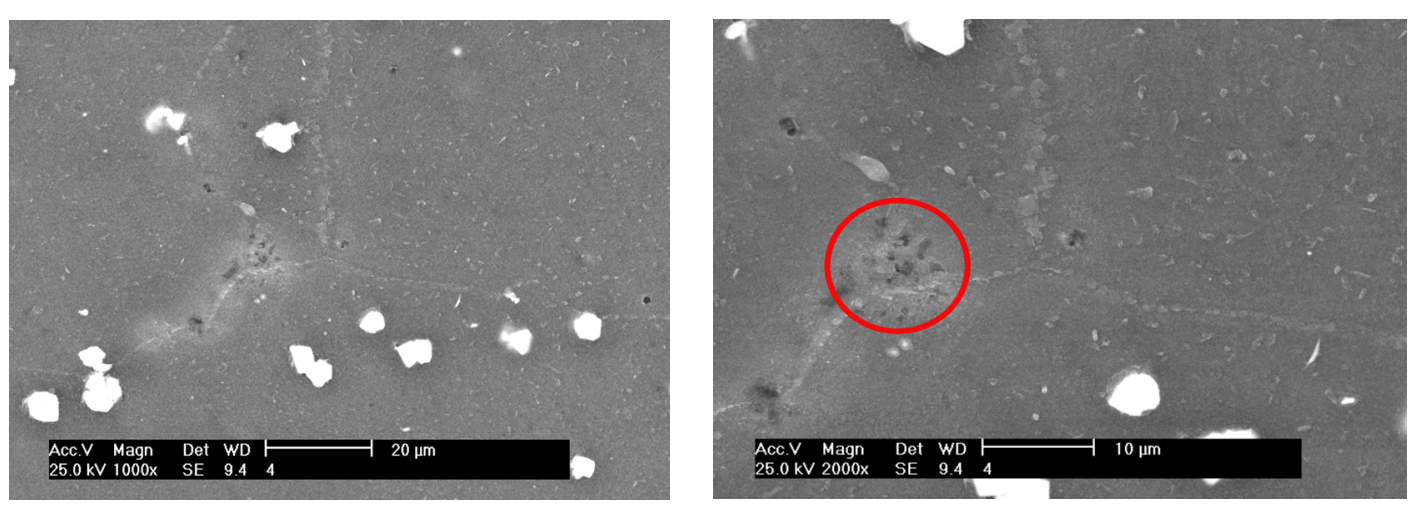

Fig. 5: Microstructure of Mg-12Li-3Al-1.1Nd alloy at low magnification (a) and high magnification (b)

Figure 5 shows the SEM micrograph of Mg-12Li-3Al-1.1Nd alloy. Figure 5(a) shows that, compared with Fig. 3(a), the change in number of granular $\mathrm{Al}_{2} \mathrm{Nd}$ phase is smaller, but the size is larger. However, the needle-like $\mathrm{Al}_{11} \mathrm{Nd}_{3}$ phase is smaller and the number is much less. In the red circle of Fig. 5(b), there are some obvious holes at grain boundary, and the gray precipitated phases in the matrix significantly increase. Figure 6 shows the XRD result of Mg-12Li-3Al-1.1Nd alloy, which indicates that the matrix is single phase $\beta(\mathrm{Li})$, and there are $\mathrm{Al}_{2} \mathrm{Nd}$ intermetallic compounds and some $\mathrm{MgLiAl}_{2}$ and $\mathrm{Al}_{4} \mathrm{Li}_{9}$. Compared with Fig. 4, both the intensity and the amount of the peaks of the second phases in Fig. 6 increase significantly. Moreover, $\mathrm{Al}_{4} \mathrm{Li}_{9}$ increases and AlLi disappears. 


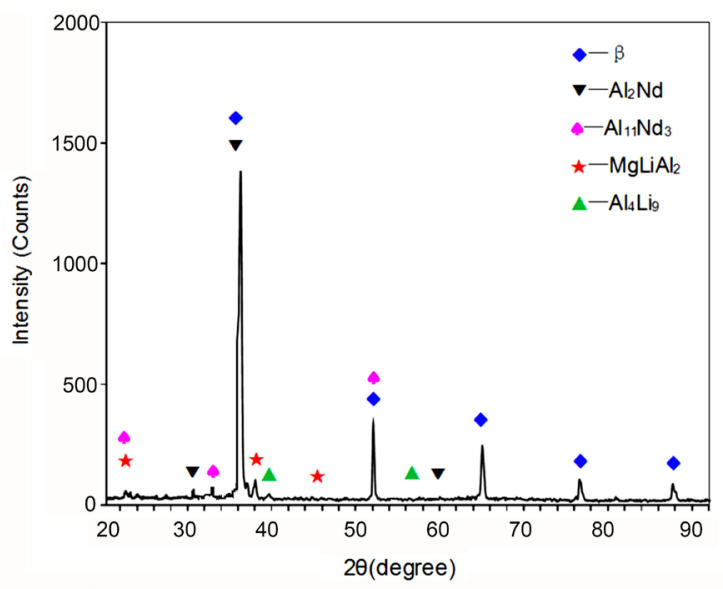

Figure 7 shows the SEM micrograph and area distribution of $\mathrm{Nd}$ element in $\mathrm{Mg}-12 \mathrm{Li}-3 \mathrm{Al}-1.1 \mathrm{Nd}$ alloy. It was evident that $\mathrm{Nd}$ element was enriched in the white particles and white needle-like phases, which further indicates that these white particles and the white needle-like phases are $\mathrm{Al}_{2} \mathrm{Nd}_{\text {and }} \mathrm{Al}_{11} \mathrm{Nd}_{3}$ respectively. $\mathrm{Al}_{2} \mathrm{Nd}$ particles were located in the matrix near the grain boundary, but not at the grain boundary, and they could hinder the long-range diffusion of other elements in the aging process.

Figure 8 is the SEM micrograph of Mg-12Li-3Al-2.0Nd. It can be seen from Fig. 8(a) that a large amount of white $\mathrm{Al}_{2} \mathrm{Nd}$ particles was generated, and aggregated at the grain boundaries

Fig. 6: X-ray diffraction pattern of Mg-12Li-3Al-1.1Nd alloy
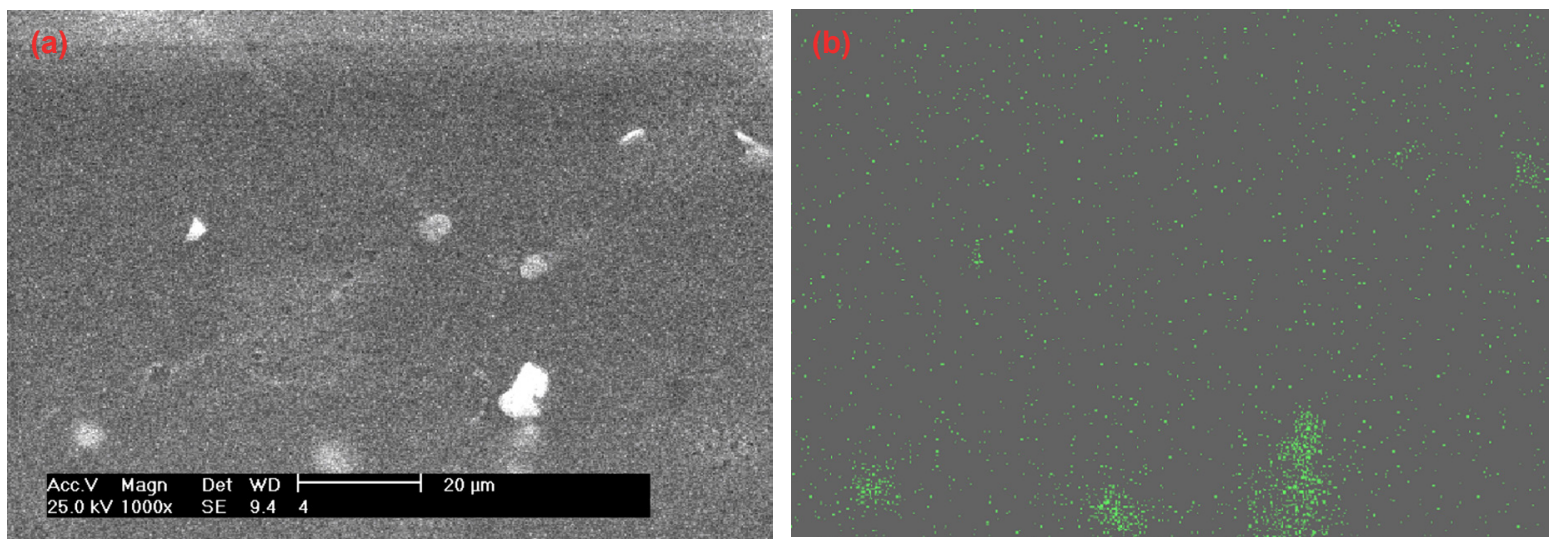

Fig. 7: SEM micrograph (a) and area distribution of Nd element (b) in Mg-12Li-3Al-1.1Nd alloy
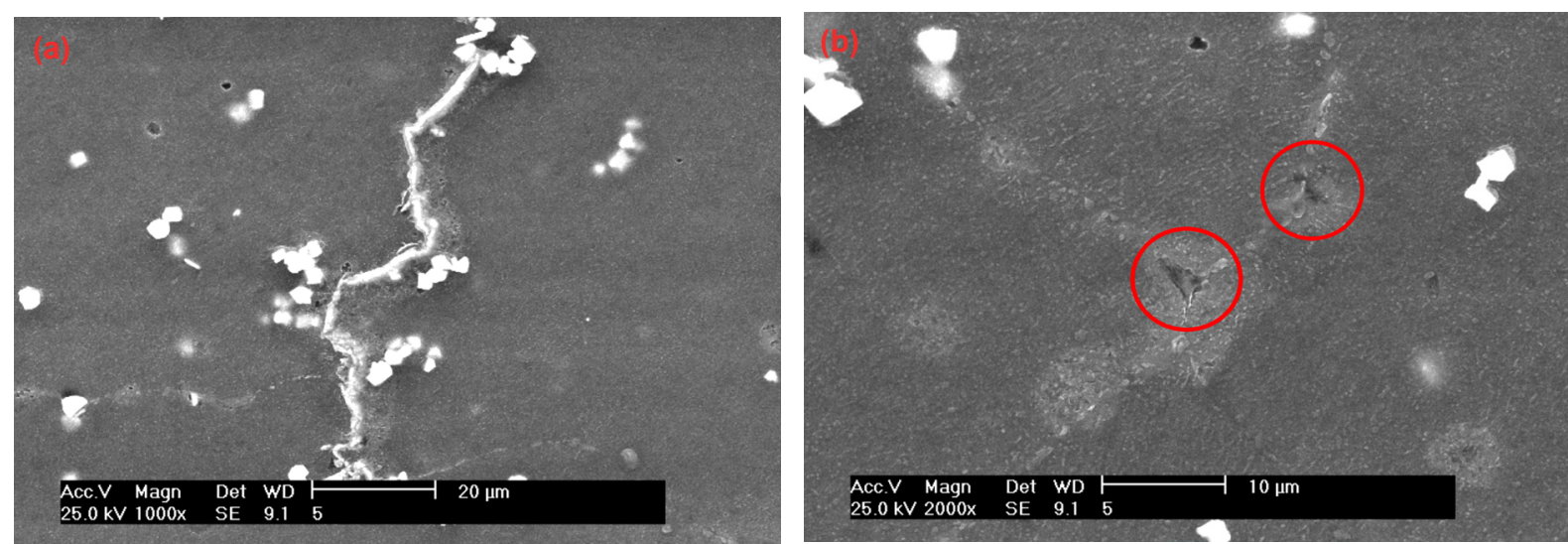

Fig. 8: Microstructure of Mg-12Li-3Al-2.0Nd alloy (a) and grain boundary (b)

and their vicinity, almost no needle-like $\mathrm{Al}_{11} \mathrm{Nd}_{3}$ phase appeared. In Fig. 8(b), there were a few voids at the grain boundary. The results of X-ray diffraction of Mg-12Li-3Al-2.0Nd alloy (Fig. 9) show that there were $\mathrm{Al}_{2} \mathrm{Nd}$ intermetallic compounds and $\mathrm{MgLiAl}_{2}$ and $\mathrm{Al}_{4} \mathrm{Li}_{9}$ on $\beta(\mathrm{Li})$ matrix; however, the peaks of $\mathrm{MgLiAl}_{2}$ and $\mathrm{Al}_{4} \mathrm{Li}_{9}$ declined, indicating these second phases became fewer.

As described above, the added $\mathrm{Al}$ can form $\mathrm{AlLi}, \mathrm{Al}_{4} \mathrm{Li}_{9}$ and $\mathrm{MgLiAl}_{2}$ phases with $\mathrm{Li}$ and $\mathrm{Mg}$. But if $\mathrm{Nd}$ is added into the $\mathrm{Mg}-12 \mathrm{Li}-3 \mathrm{Al}$ alloy, due to the larger difference in electronegativity between $\mathrm{Al}$ and $\mathrm{Nd}$ (Al: 1.61; Nd:1.20), then $\mathrm{Al}$ is easier than $\mathrm{Mg}(\mathrm{Mg}: 1.31)$ to combine with $\mathrm{Nd}$ to

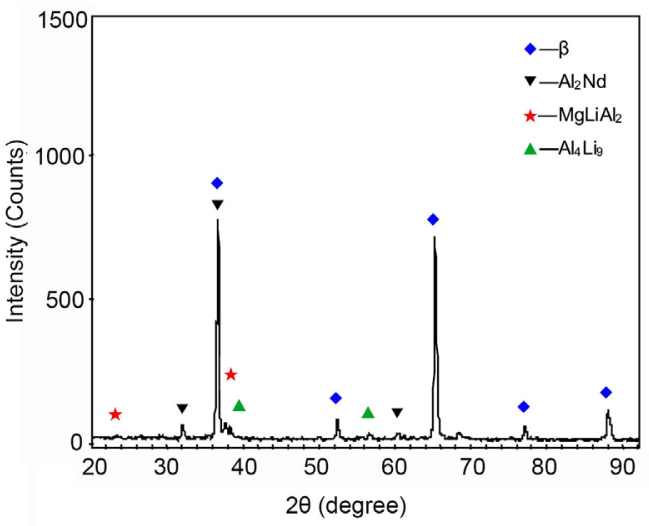

Fig. 9: X-ray diffraction pattern of $\mathrm{Mg}-12 \mathrm{Li}-3 \mathrm{Al}-2.0 \mathrm{Nd}$ alloys 
form a compound with higher stability ${ }^{[9,17]}$. Therefore, $\mathrm{Al}$ and $\mathrm{Nd}$ formed $\mathrm{Al}_{2} \mathrm{Nd}$ and $\mathrm{Al}_{11} \mathrm{Nd}_{3}$ phase in this study, which has a precipitation strengthening effect. Meanwhile, some $\mathrm{Al}$ dissolved into the matrix, which also has the solid solution strengthening effect. With the increase of $\mathrm{Nd}$ content, the Al-Nd intermetallic compounds had a trend to change from needle-like $\mathrm{Al}_{11} \mathrm{Nd}_{3}$ to granular $\mathrm{Al}_{2} \mathrm{Nd}$. $\mathrm{Al}_{2} \mathrm{Nd}$ and $\mathrm{Al}_{11} \mathrm{Nd}_{3}$ distributed near the grain boundary. But when the content of $\mathrm{Nd}$ was too high (e.g. 2.0wt.\%), the granular $\mathrm{Al}_{2} \mathrm{Nd}$ gathered into clusters in the vicinity of the grain boundary as well as at the grain boundary. In addition, with the increase of $\mathrm{Nd}$ content, $\mathrm{Al}_{4} \mathrm{Li}_{9}$ increased and AlLi disappeared.

\subsection{Mechanical properties}

\subsubsection{Microhardness}

Figure 10 shows the micro-hardness of as-cast Mg-12Li$3 \mathrm{Al}-x \mathrm{Nd}$ alloy in the natural aging process. It appeared that the micro-hardness of alloy after three days was basically the same as that of alloy after six months, which indicated that the addition of $\mathrm{Nd}$ can effectively improve the stability of the alloy at room temperature. With the increase of $\mathrm{Nd}$ content, the micro-hardness of the alloy increased firstly and then decreased, and reached the peak value of $75 \mathrm{HV}$ at $1.1 \mathrm{wt} . \% \mathrm{Nd}$. What was necessary to point out was that the poor stability at room temperature was a significant drawback of $\mathrm{Mg}$-Li alloy with single phase $\beta$, e.g. LA $141 \mathrm{~A}^{[18,19]}$.

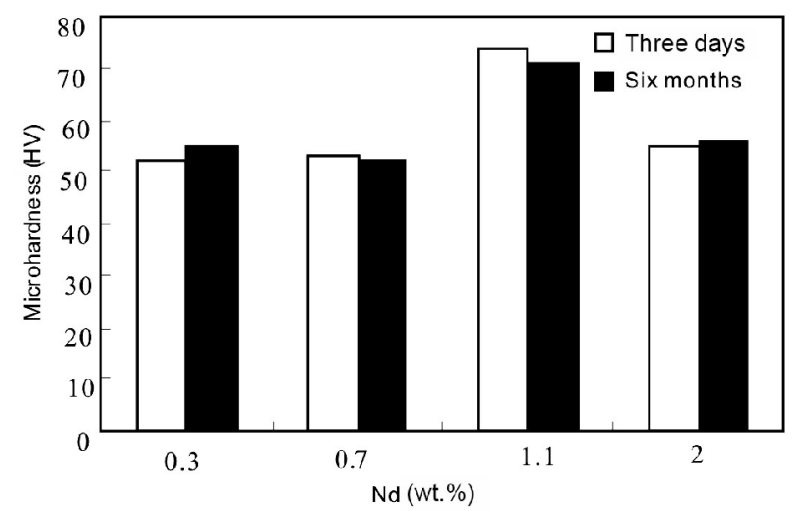

Fig. 10: Micro-hardness of Mg-12Li-3Al-xNd $(x=0.3,0.7,1.1,2.0 w t . \%)$ alloys

\subsubsection{Tensile property and fracture analysis}

(a) Tensile properties of alloy

Table 2 shows the tensile properties of the alloys. It appeared that, with the increase of $\mathrm{Nd}$ content, the tensile strength of the alloys decreased firstly then increased, and finally decreased. The tensile strength of \#3 alloy was the highest (180 MPa), but its elongation was only $9.2 \%$; while the tensile strength of \#2 alloy was only $147 \mathrm{MPa}$, but its elongation was as high as $53.7 \%$. The reasons were as follows: While it should be pointed out that the refining effect of rare earth elements on $\mathrm{Mg}$ - $\mathrm{Li}$ alloy has been proposed in some previous literatures, the analysis of the mechanism was discussed mainly from the point of view of second phases and solution strengthening in this paper.

For \#2 alloy, the actual Al content was relatively low (as in Table 1), resulting in the smaller solid solution strengthening effect of Al. Although $0.7 \mathrm{wt} . \% \mathrm{Nd}$ element was added, its solubility was very small. Owing to the addition of $\mathrm{Nd} \%$, granular $\mathrm{Al}_{2} \mathrm{Nd}$ and acicular $\mathrm{Al}_{11} \mathrm{Nd}_{3}$ intermetallic compounds formed, which further weakened the effect of solid solution strengthening of $\mathrm{Al}^{[7]}$. Moreover, if compared with the remaining samples, the amount of precipitated phases in the matrix of \#2 alloy was obviously less, which also resulted in the lower precipitation strengthening effect. Although the generated $\mathrm{Al}_{2} \mathrm{Nd}$ and $\mathrm{Al}_{11} \mathrm{Nd}_{3}$ have dispersion strengthening effect, their amount was small, hence their enhanced effect was limited. Therefore, \#2 alloy has the lowest tensile strength. Nevertheless, the tensile strength of \#2 alloy was still better than LA141A(T7). In addition, because there was almost no shrinkage hole in the microstructure, \#2 alloy exhibited excellent elongation.

In comparison, the intermetallic compound of Al-Nd formed in \#3 alloy was mostly granular $\mathrm{Al}_{2} \mathrm{Nd}$ instead of acicular $\mathrm{Al}_{11} \mathrm{Nd}_{3}$, dispersed near the grain boundaries. Compared to the acicular $\mathrm{Al}_{11} \mathrm{Nd}_{3}$, granular $\mathrm{Al}_{2} \mathrm{Nd}$ has smaller fragmentation effect to the matrix, and can play a better role in pinning the dislocation in the process of tensile deformation. Moreover, $\mathrm{MgLiAl}_{2}$ and $\mathrm{Al}_{4} \mathrm{Li}_{9}$ particles in the matrix also increased significantly. These particles have good pinning effect to dislocation in the process of tensile deformation too, so that the tensile strength of \#3 alloy was the highest. However, these particles above decreased the ductility of the alloy, and due to the existence of some obvious shrinkage at the grain boundary, the elongation of \#3 alloy was the lowest.

Compared with \#3 alloy, the solid solution strengthening effect of \#4 alloy was slightly weaker due to the smaller Al content, and the number of precipitated phase in matrix was smaller, so the tensile strength of \#4 alloy was lower than that of \#3 alloy, and the shrinkage led to the lower elongation than that of \#2 alloy. Even so, the comprehensive mechanical properties of \#4 alloy were still the best, and the tensile strength and elongation of \#4 alloy were better than that of LA141A (T7) as well.

Table 2: Mechanical properties of Mg-12Li-3Al-xNd alloys

\begin{tabular}{ccccc}
$\begin{array}{c}\text { Number } \\
\text { of alloy }\end{array}$ & Alloy & $\begin{array}{c}\text { TS } \\
\boldsymbol{R}_{\mathrm{m}}(\mathrm{MPa})\end{array}$ & $\begin{array}{c}\mathrm{EL} \\
\mathbf{A}(\%)\end{array}$ & Notes \\
\hline \#1 & Mg-12Li-3Al-0.3Nd & 163 & 23.7 & \\
$\# 2$ & Mg-12Li-3Al-0.7Nd & 147 & 53.7 & \\
$\# 3$ & Mg-12Li-3Al-1.1Nd & 180 & 9.20 & Shrinkage \\
$\# 4$ & Mg-12Li-3Al-2.0Nd & 169 & 32.5 & Shrinkage \\
& & 144.69 & 24 & \\
& & & &
\end{tabular}




\section{(b) PLC phenomenon of alloy at room temperature}

Figure 11 shows the stress-strain curves of the four alloys, which indicated that the PLC (Portevin-Le Chatelier ${ }^{[20]}$ ) phenomenon occurred during the tensile process at room temperature, and the PLC effect of \#2 and \#4 samples were especially remarkable. The reasons were as follows:

In the early stage of deformation, the beginning of dislocations in the grains must overcome the bound of solid solution atoms in the lattice. When the applied shear stress reached a certain value to free the dislocations, plastic deformation began, so the alloy exhibited obvious yield phenomenon. Because of the addition of $\mathrm{Nd}$ element, rare earth intermetallic compounds $\mathrm{Al}_{2} \mathrm{Nd}$ or $\mathrm{Al}_{11} \mathrm{Nd}_{3}$ were generated in the vicinity of grain boundaries. Moreover, there were some precipitates and solid solution atoms in the matrix near the grain boundaries as well. $\mathrm{Al}_{2} \mathrm{Nd}$ precipitates and solid solution atoms had a pinning effect for the dislocations. In the tensile process, the dislocations moved to the area near the grain boundary and piled up, resulting in a strong interaction between $\mathrm{Al}_{2} \mathrm{Nd}$, precipitates, solid solution atoms and the dislocation. It required a great external shear stress to free the dislocation from the bound of the solute atom group, $\mathrm{Al}_{2} \mathrm{Nd}$ or $\mathrm{Al}_{11} \mathrm{Nd}_{3}$ and precipitated phase. Once the dislocation was free, it moved into the adjacent grain boundaries under a much lower stress, and offset with the opposite sign dislocations, resulting in the annihilation of dislocations. This process led to a stress fluctuation, and thus caused the PLC phenomenon ${ }^{[21]}$. For \#3 alloy sample, due to the evident defects, fracture occurred in the tensile process before the pile up of a large number of dislocations had been produced in the vicinity of grain boundaries, so the stress-strain curves of the \#3 alloy samples did not show an obvious PLC phenomenon.

\section{(c) Fracture analysis of alloy}

The crystal structure of $\alpha(\mathrm{Mg})$ is hexagonal close-packed (hcp), and has only one group of slip surface (0001). When added with $\mathrm{Li}$ and $\mathrm{Al}$ alloy, the matrix of $\mathrm{Mg}$-Li transformed from

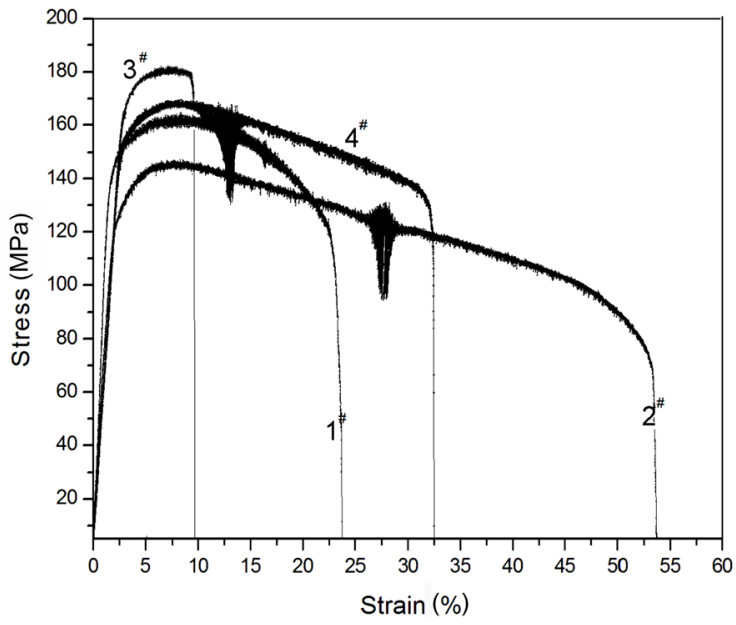

Fig. 11: Stress-strain curves of Mg-12Li-3Al-xNd $(x=0.3,0.7,1.1,2.0 w t . \%)$ alloys
$\alpha(\mathrm{Mg})$ into $\beta$ (Li), whose glide planes were (112) and (110). The increasing of slip system made the slip more easily, so the ductility of the alloy increased. After the tensile test, obvious necking can be observed on the fracture specimens except for \#3 alloy.

Figure 12 shows the tensile fracture morphology of the four alloys. There were many equiaxed dimples on the fracture of \#1 and \#2 alloys which showed obvious ductile fracture characteristics, and there was a small amount of cleavage torn edges or small cleavage steps which indicated a few characteristics of quasi cleavage fracture. The fracture of \#3 alloy has some tongue patterns but few dimples, and due to defect of shrinkage, the bright grain interface and the crystal grains can be seen in the defect area. Therefore, the fracture mode of \#3 alloy was mainly intergranular brittle fracture.

The tensile fracture of \#4 alloy also had many dimples, where a large number of small second phase particles distributed. This indicated that the second phase particles were the nucleation point of the micro-hole, whose growth and separation led to the formation of dimples. At the same time, a few tearing edges and tongue patterns could be observed. Therefore, the fracture modes of \#4 alloy basically belonged to ductile fracture, accompanied by a little quasi cleavage fracture.

It was necessary to point out that there were some obvious deformed holes on the fractures of \#1, \#2 and \#4 specimens. This phenomenon was especially remarkable on \#2 sample, where the adjacent holes connected with each other, and then became a deep groove during the deformation process. The existence of deformed holes implied the plastic deformation of the alloy was adequate.

\section{Conclusions}

(1) Mg-12Li-3Al- $x \mathrm{Nd}(x=0.3,0.7,1.1,2.0 \mathrm{wt} . \%)$ alloys were prepared, whose matrix was $\beta$ phase structure with $\mathrm{Al}_{4} \mathrm{Li}_{9}$, $\mathrm{MgLiAl}_{2}$, AlLi phase distributing on it. With the increase of $\mathrm{Nd}$ content, the Al-Nd intermetallic compounds changed from needle-like $\mathrm{Al}_{11} \mathrm{Nd}_{3}$ to granular $\mathrm{Al}_{2} \mathrm{Nd}$, distributing in the vicinity of the grain boundaries.

(2) The tensile strength of Mg-12Li-3Al-1.1Nd was as high as $180 \mathrm{MPa}$, the elongation rate of $\mathrm{Mg}-12 \mathrm{Li}-3 \mathrm{Al}-0.7 \mathrm{Nd}$ reached $53.7 \%$, and the comprehensive mechanical properties of $\mathrm{Mg}$ 12Li-3Al-2.0Nd was the best.

(3) PLC phenomenon occurred during tensile process of the alloys at room temperature.

Therefore, the $\beta$-based Mg-Li alloy with good plasticity as well as enhanced strength can be obtained by moderate addition of $\mathrm{Nd}$ and $\mathrm{Al}$.

\section{References}

[1] Zhang X, Zhang N Y, Zhang J S, et al. Thermodynamic analysis 

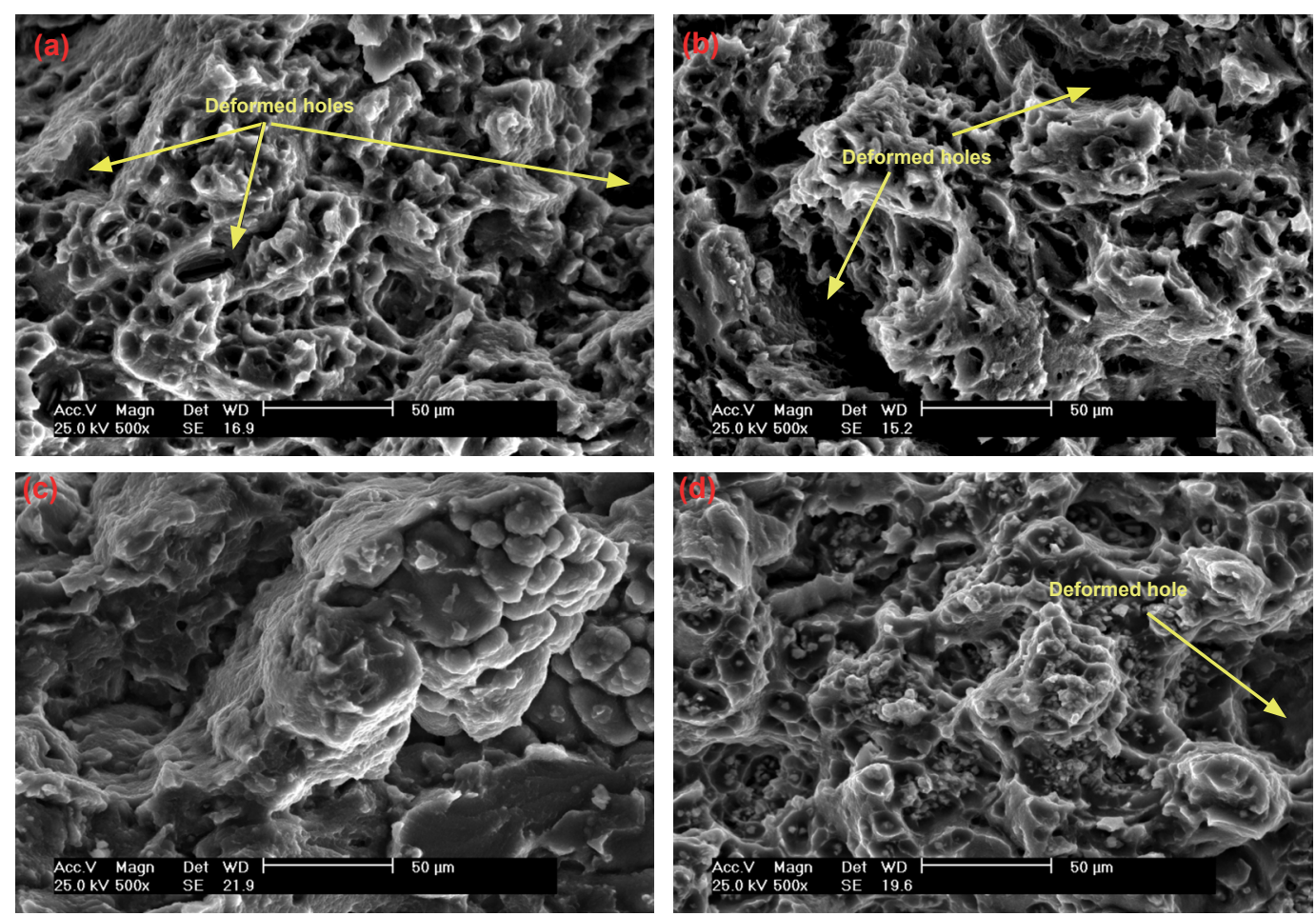

Fig. 12: Tensile fracture of Mg-12Li-3Al- $x$ Nd alloy: (a) $x=0.3$, (b) $x=0.7$, (c) $x=1.1$, (d) $x=2.0$

of Mg-Li alloys preparation by a vacuum carbothermic reduction method. Rare Metal Materials and Engineering, 2016, 45(1): 127131. (In Chinese)

[2] Yin $\mathrm{H} M$, Jiang $B$, Huang $X Y$, et al. Effect of Ce addition on microstructure of Mg-9Li alloy. Transactions of Nonferrous Metals Society of China, 2013, 23(07): 1936-1941.

[3] Zhou $Y$ Y. Influence of $\mathrm{Ca}$ adding mode on microstructure and mechanical properties of Mg-Li alloys. Dissertation, Taiyuan University of Technology, 2016. (In Chinese)

[4] Ma X L. Microstructure and properties of Mg-Li-Sn alloy. Dissertation, Xining: Qinghai university, 2016. (In Chinese)

[5] Yi H Y, Peng X D, Jiang J W, et al. Microstructure, mechanical properties and corrosion resistance of Mg-9Li-3Al-1.6Y Alloy. Chinese Journal of Rare Metals, 2013, 37(6): 863-869.

[6] Cao F R, Ding H, Li Y L, et al. Superplasticity, dynamic grain growth and deformation mechanism in ultralight two-phase magnesiumlithium alloys. Mater Sci Eng A, 2010, 527(9): 2335-2341.

[7] Zhang M L, Elkin F M. Magnesium-lithium super light alloy. Beijing: Science Press, 2010. (In Chinese)

[8] Song $Y \mathrm{~L}$, Liu $\mathrm{Y} \mathrm{H}$, Zhu X Y, et al. Effect of $\mathrm{Nd}$ on microstructure and mechanical properties of AZ91 magnesium alloy. Journal of Jilin University (Engineering and Technology Edition), 2006, 36(35): 6-10. (In Chinese)

[9] Li M, Hao H, Zhang A M, et al. Effects of Nd on microstructure and mechanical properties of as-cast Mg-8Li-3Al alloy. Journal of Rare Earths, 2012, 30(5): 492-496. (In Chinese)

[10] Cui C L, Zhu T L, Leng Z. Effects of combined addition of $Y$ and $\mathrm{Nd}$ on microstructure and texture after compression of Mg-Li alloy at room temperature. Acta Metallurgica Sinica, 2012, 48(6): 725732.

[11] Liu B, Zhang M L, Wu R Z. Effects of Nd on microstructure and mechanical properties of as-cast LA141 alloys. Materials Science and Engineering: A, 2008, 487(1-2): 347-351.

[12] Ji G D, Wu R Z, Niu Z Y, et al. Effects of Nd Content on Microstructure of As-cast Mg-11Li-1Al Alloy. Special Casting \& Nonferrous Alloys, 2009, 29(5): 461-464. (In Chinese)

[13] Chen B, Feng L P, Zhong H, et al. Microstructures and properties of a Mg-Li-Al-Zn wrought alloy. Journal of Beijing University of Aeronautics and Astronautics, 2004, 30(10): 976-979. (In Chinese)

[14] Cui C L, Wu L B, Zhang J H, et al. Influence of yttrium on microstructure and mechanical properties of as-cast Mg-5Li3Al-2Zn alloy. Journal of Alloys and Compounds, 2011, 509(37): 9045-9049.

[15] Jia D. Investigation on high strength wrought Mg-Nd-Y Alloys. Dissertation, Nanjing: Southeast University, 2009. (In Chinese)

[16] Wu Y J, Ding W J, Peng L M, et al. Research Process of Advanced Magnesium Rare Earth Alloys. Materials China, 2011, 30(2): 1-9.

[17] Zhang $\mathrm{K} \mathrm{Y}$. Effects of $\mathrm{Si}$ and $\mathrm{Nd}$ addition on microstructure and mechanical properties of Mg-11Li-3Al alloy. Dissertation, Taiyuan: Taiyuan University of Technology, 2016, 45(4): 990-996. (In Chinese)

[18] Alamo A, Banchik A D. Precipitation phenomena in the Mg-31Li1 AL alloy. Journal of Materials Research, 1980, (15): 222-229.

[19] Kazakov A K, Timonava M A, Borisova L G. Mechanical properties and workability of Mg-Li-Al $\beta$-based alloys. Metal Science and Heat Treatment, 1983, (25): 9, 10.

[20] Lin N, Yang K H, Chen W Z. Influence of precipitation on PLC effect of AZ91D pressed magnesium alloy. Transactions of Materials and Heat Treatment, 2016, 37(2): 25-30. (In Chinese)

[21] Yu T, Wang H S, Sha G Y, et al. Tensile deformation behavior and its dependence on strain rate of Mg-8\%Li alloy. Light Alloy Fabrication Technology, 2010, 38(11): 55-58. (In Chinese) 